INDO GLOBAL JOURNAL OF

PHARMACEUTICAL SCIENCES

ISSN 2249- 1023

\title{
Enhanced Biosynthesis of Gossypol in Cell Suspension Culture of Gossypium hirsutum through Elicitation by Water Soluble Carbon Nanotubes
}

\author{
Sameer Dixit, Gourav Jain, Surjeet Kumar Arya, Praveen C. Verma ${ }^{*}$ \\ CSIR- National Botanical Research Institute, Council of Scientific and Industrial Research, Rana Pratap Marg, Lucknow, UP, India
}

Address for Correspondance: Praveen C. Verma, praveencverma@yahoo.com

Keywords Carbon Nanotubes (CNTs); Gossypol; Cotton Cell Suspension Culture.

\begin{abstract}
Plant produces large number of secondary metabolites as medicinally important compounds, gossypol is one of them which is produced by Gossypium sp. It is a valuable secondary metabolite with several known properties such as anti-microbial, anticancerous and male oral contraceptive. Carbon nanotubes which are allotropes of carbon found great applicability in biological, chemical \& physical sciences because of their high surface area. In the present study, we showed that enhancement of gossypol production in cotton cell suspension culture through supplementation of water soluble carbon nanotubes in culture media. Results has also showed that the fresh and dry weights of cotton cell suspension culture grown in MS media with $20 \mu \mathrm{g} / \mathrm{ml}$ CNTs are 1.9 and 2.13 fold higher than grown in control MS media respectively after one month. The net increment of gossypol production in MS media with $20 \mu \mathrm{g} / \mathrm{ml}$ CNTs is 2.47 fold than control. Confocal \& SEM imaging showed that the CNTs are on cell surface \& forms extra channel surface which results increase in biomass production in cotton cell suspension. Cell suspension culture produce gossypol shows antiproliferative activity against prostate cancer cell line (PC-3). This new method for enhancing the gossypol production might helpful for production of other plant based biologically important compound. (C) 2016 iGlobal Research and Publishing Foundation. All rights reserved.
\end{abstract}

Conference Proceedings: International Conference on Advances in Plant and Microbial Biotechnology (PMB2017); JIIT, Noida: February 02-04, 2017

Indo Global Journal of Pharmaceutical Sciences( ISSN 22491023 ; CODEN- IGJPAI; NLM ID: 101610675) indexed and abstracted in EMBASE(Elsevier), SCIRUS(Elsevier),CABI, CAB Abstracts, Chemical Abstract Services(CAS), American Chemical Society(ACS), Index Copernicus, EBSCO, DOAJ, Google Scholar and many more. For further details, visit http://iglobaljournal.com 